\title{
Exploration and ecology in Darwin's finches
}

\author{
Sabine Tebbich $\cdot$ Birgit Fessl $\cdot$ Donald Blomqvist
}

Received: 21 June 2007/ Accepted: 14 March 2008/Published online: 30 March 2008

(C) Springer Science+Business Media B.V. 2008

\begin{abstract}
One of the main functions of exploratory behaviour is to gain information about the environment. The adaptive value of such behaviour should vary with ecological conditions influencing the diversity and stability of resources, as well as with the costs associated with gathering information. Consequently, predictions can be made about environmental factors influencing the evolution of exploration. We used comparative methods, combining a field experiment with literature data, to study correlated evolution between explorative behaviour and ecology among 13 species of Darwin's finches. Controlling for phylogenetic influences, we found that exploration (measured as the proportion of individuals responding in the experiment) increased with diet diversity and the amount of fruit in diet, consistent with theories stating that exploration aimed at finding new food types should be more beneficial for generalists than for specialists. However, our study is the first to demonstrate a correlation between neophilia and food diversity. Contrary to our prediction, species with a high percentage of concealed food in their diet were less explorative. A possible explanation for this novel finding is that in our study
\end{abstract}

S. Tebbich

Max Planck Institute for Behaviour and Physiology, Seewiesen 82319, Germany

S. Tebbich

Department of Experimental Psychology, University of Cambridge, Cambridge CB2 3EB, UK

S. Tebbich $(\bowtie)$

School of Psychology, University of St Andrews, St Andrews KY16 9JP, UK

e-mail: st50@st-andrews.ac.uk

B. Fessl

Max-Planck Institute for Ornithology, Andechs 82346, Germany

D. Blomqvist

Konrad Lorenz Institute for Ethology, Austrian Academy of Sciences, Vienna 1160, Austria

Present Address:

D. Blomqvist

Department of Zoology, University of Gothenburg, Box 463, 40530 Gothenburg, Sweden 
system concealed food may be a stable resource, and species using such resources should be less dependent on the discovery of new food types.

Keywords Comparative methods - Correlated evolution - Ecological conditions · Exploratory behaviour $\cdot$ Neophilia

\section{Introduction}

In a changeable environment, animals may benefit from obtaining information on the state and variability of crucial resources such as food, nest material, predators, companions and mates. However, it may be costly to obtain such knowledge. Moreover, depending on just how changeable the environment is, the utility of the information gathered will vary. One way to learn and gather information about the environment is exploratory behaviour. Two forms of exploration can be distinguished; intrinsic and extrinsic exploration. In intrinsic exploration, information gathering is the main purpose of the behaviour, whereas in extrinsic exploration information is taken up in the course of another activity such as foraging (Winkler and Leisler 1999). Experimental evidence for object exploration that is not related to foraging, i.e. intrinsic exploration, exists for several taxa (Glickman and Sroges 1966; Heinrich 1995; Mettke 1995; Mettke-Hofmann et al. 2002). In order to learn about the quality and property of familiar as well as novel objects, animals approach and possibly manipulate them. There is a considerable variation among species in the readiness and intensity of approaching and exploring new situations or objects (Mettke-Hofmann et al. 2002). Exploratory behaviour may be motivated by neophilia, which is defined as the spontaneous attraction of an animal to a food item, place, or object because it is novel. In contrast, neophobia is defined as the avoidance of novel objects, which should inhibit approach to novel situations or objects (Thorpe 1956). Neophilia and neophobia may be seen as a continuum of one behavioural trait, but there is also some empirical evidence suggesting that they are two independent behavioural responses to a novel stimulus (Chance and Meade 1955; Hughes 1997; Montgomery 1955; Russel and Pearce 1971). If an animal is confronted with a novel situation both approach and avoidance is often elicited. Since the behavioural response is often driven by a combination of these factors, they are not easily separated empirically. Neophilia may be driven by the benefits of exploration which are thought to be the discovery of new resources, finding new patches of familiar resources or developing new means of obtaining familiar resources, whereas neophobia may be driven by the costs of exploration; e.g. risk of predation (Greenberg and Mettke-Hofmann 2001).

The costs and benefits of exploration are influenced by several ecological factors, which may account for the striking differences in exploratory behaviour found among species (Mettke-Hofmann et al. 2002). One of these factors is diet breadth, which is expected to affect the value of discovering new resources. The latter should be more advantageous for a generalist than for a specialist (Greenberg and Mettke-Hofmann 2001). Exploitation of new resources is also favoured by few competing species (which leads to broadening of feeding niches), as well as by food limitation and instability of food resources (Morse 1980). The other benefits of exploration, i.e. finding new patches of familiar resources or developing new means of obtaining familiar resources, are thought to be associated with certain food types. Thus, food types that are difficult to find because they are concealed (e.g. insects under moss), or patchily distributed in space or time (e.g. fruit) should favour 
the development of sustained investigatory activity (Day et al. 2003; Glickman and Sroges 1966; Mettke 1995; Mettke-Hofmann et al. 2002). Additionally, food that is difficult to extract from a substrate (e.g. nuts or insects under the bark) and therefore vary substantially in handling time, should favour persistent exploratory activity to arrive at a good estimate of the variance in food accessibility (Winkler and Leisler 1999). Support for both predictions comes from a study on parrots, which reported that latencies to approach novel objects decreased with increasing amount of fruit in the diet, whereas the duration of exploration correlated positively with the content of nuts in the diet (Mettke-Hofmann et al. 2002). The costs of explorations are mainly thought to be related to predation risk and energetic costs. For example, low density or absence of predators reduces the cost of exploration and therefore enhances opportunities to experiment with new types of behaviour (Morse 1980).

Island life combines several of these factors, which may explain the famous fearlessness and curiosity of island species (Bruner 1974; Grant 1986; Holyoak 1973; Yeaton 1974). For instance, island species normally have fewer competing species and therefore broader niches than species or populations from the mainland (Ebenman and Nilsson 1982; Yeaton and Cody 1974). They are usually also less exposed to predators, which reduces the costs of exploration and favours the use of alternative resources. Especially for species living on small islands, resources are limited and the discovery of new food types is crucial (Pulliam 1986).

The Darwin's finches seem ideal for testing the influence of ecological factors on the evolution of exploratory behaviours. This group of closely related passerine birds is restricted to islands and shows high levels of exploration (Bowman 1961; Curio and Kramer 1964; Grant 1986). However, Darwin's finches also show marked inter-specific differences in ecology, which may cause variation in exploratory behaviours. Both diet breadth and food types thus vary between the two main groups of Darwin's finches, the ground finches (mainly seed-eaters) and the tree finches (mainly insectivorous). However, there is also considerable variation within each of these groups (Grant 1986). Additionally, on the Galapagos Islands climate and associated plant communities vary along an altitudinal gradient, ranging from very dry coastal areas to lush, food rich cloud forests at higher altitudes (Jackson 1993). Therefore, the ecological conditions, especially the availability, abundance and stability of food resources, vary between islands with low and high elevation. As a consequence, these ecological conditions show marked variation between but also within species, depending on their geographical distribution. Another factor influencing the benefits of exploration, the number of competing species, is a function of island size and thus also differs between islands.

In general, environmental conditions on the Galápagos Islands are harsh and unpredictable (Grant 1985). In order to survive there, Darwin's finches utilize unusual resources for passerines and have developed extraordinary behaviours to exploit them. The woodpecker finch Cactospiza pallida and the mangrove finch $C$. heliobates use twigs or thorns to probe arthropods out of tree holes (Eibl-Eibesfeldt 1961). The sharp-beaked ground finch Geospiza difficilis pecks at the developing feathers of seabirds, draws blood and drinks it (Bowman and Billeb 1965). It also cracks eggs by pushing them against a rock with its feet (Grant 1986). The discovery of such resources may be a consequence of a high degree of exploratory behaviours.

The aim of our study was to investigate the role of ecology for the evolution of exploratory behaviours in Darwin's finches. Using comparative methods, we tested whether exploration, measured as neophilia, correlated with different aspects of the species' ecology. We performed a field experiment to examine differences in exploratory behaviours among 13 species 
of Darwin's finches and combined these results with literature data on various ecological factors. Based on previous studies (see above), we predicted that exploration correlates with several ecological factors influencing the benefits of exploration. First, exploration should correlate positively with diet diversity (breadth) since discovering novel resources should be more advantageous for generalists than for specialists. Second, we predicted that exploration also correlates positively with the amount of concealed food in the diet (e.g. insects that are imbedded within an inedible substrate). Food items that are hidden in substrates such as moss or bark may be hard to find and should therefore favour sustained exploratory behaviour. Moreover, if food is concealed in rigid substrates such as bark, it might be hard to extract, leading to persistent exploration. Third, since fruits are patchily distributed and need close investigation to assess edibility, exploration should increase with the proportion of fruits in the diet. Finally, because an increase in the number of potential competitors is expected to result in a decrease in diet breadth, we predicted that exploration correlates negatively with the number of sympatric species present on the island, as well as with island size and altitude (which both may predict the number of species present on the island). Also, food may be more abundant and/or stable on large islands, making the discovery of new resources (i.e. exploration) less important there than on small islands.

\section{Materials and methods}

\section{Study area}

On the Galápagos Islands, the climate is unusually dry and seasonal for the tropics. There are two main seasons; a warm and wet period, typically from January to May, and a dry and cool period for the remainder of the year (Jackson 1993). Additionally, the onset and amount of rainfall is highly variable between years and Darwin's finches can experience extreme food limitations during dry years (Grant 1985).

Rainfall within the archipelago also varies locally and with altitude, thus creating distinct vegetation zones on the higher islands (ranging from the arid zone near the coast, to a transitional forest at medium elevation, a cloud forest at higher elevations and a fern sedge grass zone; Jackson 1993). Exploratory behaviours were studied on three islands: Santa Cruz $\left(0^{\circ} 38^{\prime} \mathrm{S}, 90^{\circ} 28^{\prime} \mathrm{W}\right)$, Genovesa $\left(1^{\circ} 15^{\prime} \mathrm{S}, 90^{\circ} 30^{\prime} \mathrm{W}\right)$ and Floreana $\left(0^{\circ} 20^{\prime} \mathrm{N}\right.$, $\left.89^{\circ} 90^{\prime} \mathrm{W}\right)$. All vegetation zones are present on Santa Cruz and Floreana. On Genovesa, only the arid and transitional zones are present.

\section{Study species}

The Darwin's finches form a monophyletic group of 15 species (Petren et al. 1999), of which 14 species are endemic for the Galápagos Islands. These finches constitute a classical example of adaptive radiation. Species mainly differ in beak morphology but also in body size, reflecting adaptation to different diets (Grant 1986). We studied 13 of the species occurring on the Galápagos Islands (Appendix 1), excluding only the mangrove finch, the rarest of the Darwin's finches (Dvorak et al. 2004; Grant and Grant 1997).

\section{Field experiment}

We performed the experiment in 2000: 18 January-7 March on Santa Cruz, 13-16 March on Genovesa and 25-30 March on Floreana. We aimed to investigate intrinsic exploration, 
i.e. when information gathering was the main purpose of the observed behaviour. In order to measure intrinsic exploration, it is crucial to use objects that are not likely to be associated with foraging, nest building or mating. We therefore used a variety of novel objects that were visually distinct from food and nest material (see below). Choosing objects that are novel and not related to any biological context also minimized differences in attractiveness between species, a potentially confounding effect that needs to be considered in empirical studies of exploration.

We performed the experiment during the wet season, i.e. when food is not scarce, to ensure that finches do not primarily search for food, which otherwise may influence their motivation and therefore yield different results. It has been demonstrated that in some bird species individuals explore less, and in others more, when they are hungry (Winkler and Leisler 1999). In addition, collecting data during the wet season removed possible confounding effects of age structure. In Darwin's finches (personal observations) as in other bird species (Heinrich 1995; Pellis 1981), juveniles are known to be more explorative than adults. However, not many juveniles had fledged when we performed the experiment (the few that were seen were easily identified and subsequently excluded from the analyses). Exploration can be measured either as fear of new objects (neophobia) or as attraction to new objects (neophilia). Neophilia may be driven by the need to discover and learn new resources, whereas neophobia may be driven by predator avoidance or by the risk imposed by the objects themselves (Greenberg and Mettke-Hofmann 2001). The predation pressure on adults may be similar for all Darwin's finches: two species of owls are the only native predators on adult finches and at least one of these owls occurs on most islands (Jackson 1993). Neophobia tests are usually conducted by placing a novel object near a feeder. By looking at the difference between the time to approach a feeder in the presence or absence of a novel object, the effect of the novel object can be measured (Greenberg 1983, 1984). In neophilia tests, objects are placed alone and should attract the animals to explore them without additional stimuli. Due to the conservation restrictions on the Galápagos Islands, it was impossible to attract finches to artificial feeding sites and test their tendency for neophobia. Therefore, we were only able to conduct a neophilia experiment (assuming that the motivation for approaching novel objects reflected neophilia).

Exploration was tested by placing three novel objects simultaneously in the finches' natural environment. The objects were: one white roller brush (length $14 \mathrm{~cm}$, diameter $6 \mathrm{~cm})$, one black, folded bicycle-tube $(15 \times 7 \mathrm{~cm})$ and a pair of white, flexible plastic tubes $(20 \times 1.5 \mathrm{~cm})$ bound together with a string. We placed the objects on trees $5-7 \mathrm{~m}$ above the ground using a pole and on bushes 1.5-2 $\mathrm{m}$ above the ground in areas with low vegetation. The objects were placed approximately $1 \mathrm{~m}$ apart from each other and immediately removed after the experiment. We attracted finches by using a bird whistle during $1 \mathrm{~min}$, at a distance of $12 \mathrm{~m}$ from the objects. After $1 \mathrm{~min}$, the presence of Darwin's finches and other bird species within a radius of $10 \mathrm{~m}$ around the objects was recorded, and species, sex and age (juvenile or adult) determined. Two radii (10 and $3 \mathrm{~m}$ ) were determined using a measuring tape and marked with a little twig. We recorded the birds' behaviour from a distance of $12 \mathrm{~m}$ from the objects, using binoculars.

During 10 min-trials, we recorded the mean time spent within a radius of $3 \mathrm{~m}$ from the object (duration of exploration), and the mean time from arrival to approach within $3 \mathrm{~m}$ (latency). However, a relatively large proportion of the birds did not approach at all within $10 \mathrm{~min}$ and could not be included in these measurements. Therefore, we introduced a third estimate of exploration that took into account the number of individuals that did not approach within the experimental period. For each species, we thus calculated the proportion of individuals present within a radius of $10 \mathrm{~m}$ that approached within $3 \mathrm{~m}$ of the object during 
the experiment. However, calculating this proportion per sample point would often result in the value 0 or 1 (at many sample points only one individual per species was present at the start of the experiment). We therefore pooled the data from all sample points and calculated (per species) the ratio between the total number of individuals approaching within $3 \mathrm{~m}$ and the total number of individuals present within $10 \mathrm{~m}$. This resulted in a single percentage value per species and island. The proportion of birds that approached the object during the experiment can be seen as an indirect measurement of latency of exploration, and we subsequently refer to this measurement as "the proportion of individuals responding".

Our three behavioural measurements reflect different aspects of exploration. The decision to approach and explore a novel object or situation may primarily depend on the value of information, which should vary with ecological factors such as habitat complexity or diet breadth (Mettke-Hofmann et al. 2002). The underlying mechanism is probably curiosity or neophilia (Greenberg and Mettke-Hofmann 2001; Winkler and Leisler 1999). The latency to approach is most likely influenced by the interplay between neophilia and neophobia, with the latter primarily influenced by the cost of exploration (Greenberg and Mettke-Hofmann 2001). Duration of exploration may be more related to the handling time required to access food (Mettke-Hofmann et al. 2002; Winkler and Leisler 1999).

To avoid repeated measurements of behaviour on the same individual (approach to the objects, duration of exploration and latency), we either only included individuals that were clearly distinguishable by plumage characteristics, or measured only one individual per species and site (when more than one individual was present). To further minimize the risk of pseudo-replication, sample points were located at least $500 \mathrm{~m}$ apart. In total, we recorded exploratory behaviours at 242 locations (sample points) on three islands.

\section{Ecological data}

The ecological data were obtained from the literature, including island size and altitude (Bowman 1961), number of sympatric species (Grant 1986) and proportions of different food types (Appendix 2 and references therein). For five species (woodpecker finch, small tree finch, large tree finch Camarhynchus psittacula, vegetarian finch Platyspiza crassirostris and warbler finch Certhidea olivacea), diet data were available from two vegetation zones: the Arid and the Scalesia zone on Santa Cruz Island (Tebbich et al. 2004). Diet diversity was calculated using the Shannon Diversity Index $(\mathrm{H})$. When classifying the different food types, we were limited by the categories used by previous studies and therefore had to generalize them by merging different food types (Appendix 2). We defined concealed food as any food type embedded or hidden in an inedible substrate, e.g. insects under bark or in tree holes. In contrast, fruits, flowers, seeds and insects on the surface of a substrate were classified as non-concealed food. The proportion of these food types was calculated from the total.

\section{Comparative analyses}

We related inter-specific differences in exploration to the ecological conditions prevailing on the three islands where we performed the field experiment. For six species, we recorded exploratory behaviours on more than one island. However, species-specific data on food choice and diversity were not available for all islands, so we only included one island data set per species in the analyses (selecting the island with data on exploration as well as all the ecological variables; Appendix 1 and 2). 
We examined the relationships between exploration and ecology using phylogenetically independent contrasts (Felsenstein 1985), as implemented by Purvis and Rambaut (1995). We thus calculated contrasts (differences) in exploration between pairs of species or higher taxa in the phylogeny and correlated them with the corresponding contrasts in ecology. We standardized the contrasts by setting branch lengths to unity (i.e. assuming equal rates of evolutionary change per unit branch length throughout the phylogeny) and dividing each contrast by its standard deviation (Felsenstein 1985; Harvey and Pagel 1991; Purvis and Rambaut 1995).

Price (1997) suggested that assessing correlated evolution using species values, i.e. not correcting for the influence of phylogeny, can sometimes be justified (but see Felsenstein 1985; Harvey and Pagel 1991). Furthermore, differences between species and contrast correlations may be biologically informative (see Price 1997). In our study, however, species values and independent contrasts produced consistent results (not shown), as found previously (e.g. Mank and Avise 2006).

Several questions regarding the phylogeny of the Darwin's finches remain unanswered (see Zink 2002). However, two recent molecular studies agree in some important respects. Both of these studies, based on variation in nuclear (Petren et al. 1999) and mitochondrial DNA (Sato et al. 1999), respectively, suggest that the Darwin's finches have originated from a single ancestral species, with the ground finches (Geospiza) and the tree finches (Camarhynchus and Cactospiza) forming two monophyletic groups. They also include the Cocos Island finch Pinaroloxias inornata among the Darwin's finches, and place Certhidea olivacea at the base of the phylogenetic tree (Petren et al. 1999; Sato et al. 1999). Here, we present results based on Petren et al.'s phylogeny, which includes $C$. fusca as a separate species (Fig. 1). Recent work supports that C. fusca and C. olivacea should be treated as two distinct species (Petren et al. 2005; Tonnis et al. 2005). Calculating the independent contrasts using Sato et al.'s phylogeny yielded qualitatively similar results. Thus, all significant correlations between exploration and ecology based on this phylogeny were also significant when Petren et al.'s phylogeny was used for calculating the contrasts (Table 1).

Recently, Petren et al. (2005) demonstrated intra-specific genetic variation among Darwin's finches. This new phylogeny suggests a partly different topology compared to their earlier one (Petren et al. 1999). In particular, some of the populations of Geospiza difficilis seem to have diverged earlier than previously thought (after the divergence of Certhidea olivacea but before all other species began to differentiate). Also, the population of Geospiza conirostris breeding on Española has diverged from the one on Genovesa, as well as from populations of G. scandens (among which G. conirostris previously was nested; Petren et al. 1999). However, we did not record exploratory behaviours on any of the islands where G. difficilis had diverged early according to the new phylogeny. Moreover, we studied this species as well as G. conirostris on Genovesa, where the phylogenies appear to concur for these two species (cf. Petren et al. 1999, 2005).

We tested the relationships between exploration and ecology with linear regression analysis, and present the F-statistics for the null hypothesis that the slope equals zero (i.e. no influence of ecology on exploration). All regressions were forced through the origin because the mean value of independent contrasts is expected to be zero under the null hypothesis (Harvey and Pagel 1991). We checked the assumption of normality by inspecting the residuals from each regression. In all cases, residuals were approximately normally distributed and showed no apparent relationship with the independent variable. 


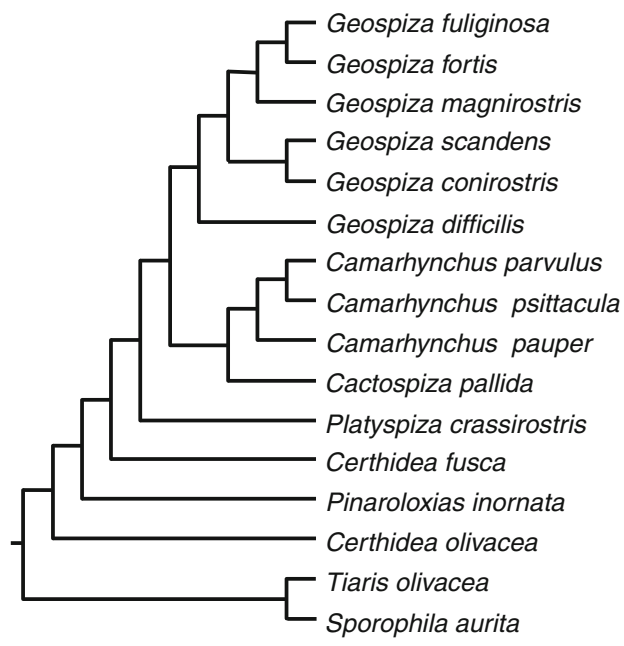

Fig. 1 Phylogeny of the Darwin's finches (excluding the mangrove finch Cactospiza heliobates) based on microsatellite DNA length variation and reconstructed using $\mathrm{G}_{\mathrm{ST}}$ and UPGMA (Petren et al. 1999). Branch lengths were set to unity. Tiaris olivacea (yellow-faced grassquit) and Sporophila aurita (variable seedeater) are two continental species believed to be the closest mainland relatives of the Darwin's finches (Petren et al. 1999 and references therein)

Table 1 Regression analyses of co-variation between exploration and ecology in Darwin's finches

\begin{tabular}{llcc}
\hline Ecological variable & Exploration & $F(n)$ & $P$ \\
\hline Island size & Proportion $^{\mathrm{a}}$ & $0.77(12)$ & 0.40 \\
& Duration $^{\mathrm{b}}$ & $0.02(12)$ & 0.89 \\
& Latency $^{\mathrm{c}}$ & $4.47(12)$ & 0.06 \\
Diet diversity & Proportion & $14.51(8)$ & $0.007^{*}$ \\
& Duration $^{*}$ & $0.05(8)$ & 0.82 \\
Concealed food & Patency & $2.94(8)$ & 0.13 \\
& Duration & $7.01(8)$ & $0.03^{*}$ \\
Proportion fruit & Latency & $0.01(8)$ & 0.93 \\
& Proportion & $6.32(8)$ & 0.04 \\
& Duration & $16.85(8)$ & $0.005^{*}$ \\
& Latency & $0.01(8)$ & 0.91 \\
\hline
\end{tabular}

Relationships were examined using phylogenetically independent contrasts based on the phylogeny presented by Petren et al. (1999). Asterisks denote results that were statistically significant $(P<0.05)$ also with an alternative phylogenetic hypothesis (Sato et al. 1999). Sample size $(n)$ refers to the number of independent contrasts

${ }^{\text {a }}$ Proportion of individuals present within a radius of $10 \mathrm{~m}$ that approached within $3 \mathrm{~m}$ of the object during the experiment

b Mean time spent within a radius of $3 \mathrm{~m}$ from the object

c Mean time from arrival to approach within $3 \mathrm{~m}$ of the object 


\section{Results}

Behavioural response

At 221 of the 242 sample points, a total of 516 Darwin's finches were present after using the bird whistle. The mean number of birds present (Darwin's finches and other passerines) was 3.5 ( $\mathrm{SD}=2.1$, range $1-12)$, and the mean number of species present was 2.4 $(\mathrm{SD}=1.1$, range $1-6)$. In total, 246 Darwin's finches $(47.7 \%$ of the total) approached within $3 \mathrm{~m}$ or less. However, we were only able to record the duration of exploration for 224 individuals and latency for 109 individuals. Mean duration of exploration was $55 \mathrm{~s}$ $(\mathrm{SD}=60$, range $2-300 \mathrm{~s})$, and mean latency was $167 \mathrm{~s}(\mathrm{SD}=13$, range 0-600 s).

\section{Correlations among variables}

Island size is strongly correlated with island altitude (Spearman rank correlation, $r_{\mathrm{s}}=0.93, P<0.001, n=14$ islands) as well as the number of species of Darwin's finches present on the island (minimum number: $r_{\mathrm{s}}=0.82, P<0.001$; maximum number: $r_{\mathrm{s}}=0.61, P=0.02 ; n=14$ islands). Of these variables, we therefore only included island size in the analyses. In contrast, our three measures of exploration were not significantly correlated (Spearman rank correlation, $P>0.17, n=13$ species).

Influence of ecology on exploratory behaviours

As predicted, we found a positive relationship between the proportion of individuals responding and diet diversity $(P=0.007$; Fig. 2a, Table 1$)$. This measure of exploration correlated positively also with the percentage of fruit in the diet $(P=0.005$; Fig. $2 b$, Table 1). Contrary to our prediction, the proportion of individuals responding was negatively correlated with the percentage of concealed food in their diets $(P=0.03$; Fig. 2c, Table 1). Finally, latency increased with an increasing proportion of concealed food in the $\operatorname{diet}(P=0.04$; Table 1$)$. Other relationships between exploration and ecology were not statistically significant $(P \geq 0.06$; Table 1$)$.

\section{Discussion}

We found that exploratory behaviour in Darwin's finches correlates with several aspects of their feeding ecology. Furthermore, controlling for phylogenetic effects using two different phylogenetic hypotheses yielded consistent results. Although we cannot rule out confounding factors (see e.g. Price 1997), our findings suggest correlated evolution between exploration and feeding ecology in the Darwin's finches. It is possible that we could have found stronger effects during the dry season, because it is plausible that the finches are more explorative during this time of the year. However, we see no reason why the patterns we detected in the wet season should disappear or reverse during the dry season.

We found no significant correlations among our three measures of exploratory behaviour, which may reflect that they are independent constituents of exploration (Winkler and Leisler 1999). However, Webster and Lefebrve (2001) reported a positive correlation between latency to approach a novel apparatus and the duration of contact. With one exception (the relationship between latency and amount of concealed food in the diet), only 



Fig. 2 Exploration (measured as proportion of individuals responding in a field experiment) and feeding ecology in Darwin's finches. The graphs show the relationships between standardized linear contrasts in exploration and (a) diet diversity, (b) proportion of fruit in the diet, and (c) proportion of concealed food in the diet

the proportion of responding individuals correlated significantly with the ecological factors. One possible explanation for why we found no significant relationships when using latency or duration of exploration may be that these measurements do not consider the birds that do not approach within the experimental period. They therefore disregard more neophobic individuals that might need longer time to approach or perhaps would not approach at all.

As predicted, exploration (measured as the proportion of individuals responding) increased with diet diversity. This result is consistent with previous studies reporting a relationship between generalist behaviour and exploration (measured either in neophilia or neophobia experiments; e.g. Greenberg 1984, 1990; Mettke-Hofmann et al. 2002; Webster and Lefebvre 2001; but see Day et al. 2003). However, only one of these studies examined exploration in a large species group while correcting for phylogenetic influences. MettkeHofmann et al. (2002) conducted tests on 61 species of parrots in captivity and found that species that typically dwell in complex habitats such as forest edges are more neophilic 
than those living in more uniform habitats. Greenberg $(1984,1990)$ showed that generalist species of warblers (e.g. chestnut-sided warbler Dendroica pensylvanica) and sparrows (e.g. song sparrow Melospiza melodia) are less neophobic than their more specialized congeners (e.g. bay-breasted warbler D. castnea and swamp sparrow M. georigiana). Similarly, the bananaquit Coereba flaveola, a foraging generalist, is less neophobic compared to the specialized lesser Antillean bullfinch Loxigilla noctis (Webster and Lefebvre 2000). Our study is, however, the first to demonstrate a positive correlation between exploration measured as neophilia and diet diversity.

The positive correlation between proportion of individuals responding and amount of fruit in their diets was also predicted and in line with previous findings. In a comparative study, Mettke-Hofmann et al. (2002) thus found that short latencies of exploration were associated with high amounts of buds and fruits in the diet.

We did not, however, predict the negative relationship between exploration and proportion of concealed food in the diet. Moreover, latency correlated positively with the amount of concealed food, supporting a negative relationship between exploratory behaviour and concealed food. One possible explanation for these novel findings may be that concealed resources are more stable and predictable in supply compared to food that is not concealed (Ellis et al. 1976; Sherry 1990). If so, species that rely on such predictable resources should be less dependent on the discovery of new food types and can therefore afford to be less explorative. Indeed, the Neophobia Threshold Hypothesis suggests that selection does not favour high levels of exploration in species that specialize on predictable resources (Greenberg 1983; Greenberg and Mettke-Hofmann 2001). This hypothesis addresses the proximate regulation of ecological plasticity and assumes that the same factors that select for neophobia also select for specialization. It posits that the degree of neophobia will strongly determine the probability that new resources will be investigated and hence incorporated into the niche of an individual. Specialists will thus remain such because they are neophobic, whereas generalists may broaden their niche because they are more likely to explore their environment.

An alternative explanation for the correlations between exploratory behaviour and feeding ecology could be that the movement patterns of Darwin's finches differ among species, thereby perhaps influencing the likelihood to unintentionally move within close distance to the experimental objects. Since we did not record the birds' natural movement patterns, our study does not permit an evaluation of this possibility. Due to the relatively large size of the objects, however, we consider it unlikely that the birds approached the objects without actually noticing them. Although the finches usually approached the objects without manipulating them, $18 \%$ of the birds obviously visually inspected the objects (44 out of 246 birds that approached within $3 \mathrm{~m}$ ). However, it is very likely that birds that approached the objects within $3 \mathrm{~m}$ also inspected them. Visual inspection can be difficult to detect in birds because of the lateral position of their eyes and because it can be very brief. Winkler and Leisler (1999) noted that a brief glance at an object may suffice for a bird to assess the state or quality of a resource. In captivity, woodpecker finches soon approached objects of similar size and structure, but it often took several hours until they started manipulating them (S. Tebbich and B. Fessl, unpublished).

Another ecological influence on exploratory behaviour may be size and composition of the groups of birds present at the start of the experiment. The social context has been shown to encourage, or to delay object exploration. Birds in groups show less neophobia than solitary ones (Coleman and Mellgren 1994). Furthermore, the order of approach and duration of exploration are influenced by the dominance hierarchy within the group, 
including interactions between individuals of the same or different species (e.g. Katzir 1982; Mettke-Hofmann et al. 2002; Stöwe et al. 2006). Given that our experimental period was $10 \mathrm{~min}$, however, we think that it is unlikely that dominance hierarchies influenced the proportion of approaching individuals. Mean duration of exploration was $55 \mathrm{~s}$, and the mean number of birds exploring was 3.5. Therefore, at most sample points the experimental period was sufficient for most individuals to approach.

In summary, our results suggest correlated evolution between exploratory behaviour and feeding ecology in Darwin's finches. Consistent with theoretical predictions, we show that the intensity of exploration correlates positively with diet diversity and the amount of fruit in the diet. Unexpectedly, species with a higher percentage of concealed food in their diet are less explorative. The most likely explanation for this result is that, at least in Darwin's finches, concealed food resources may be more stable than those that are not concealed. Our results thus imply that the expected relationship between exploration and hidden food in some cases may need to be modified by taking resource stability into account.

Acknowledgements We thank the Galápagos National Park Service and the Charles Darwin Research Station for support, TAME for reduced tickets and especially W. Wickler and E. Gwinner for enabling the study. S. Torres Baéz and C. Vinueza helped with data collection. We are also grateful to the crew of the Beagle: Captain B. Gutierrez and V. Barzola and administrator E. Yánez. C. Mettke-Hofmann and H. Winkler provided constructive input during the planning of the study, and A. Pauliny, G. Thomas and anonymous reviewers gave valuable comments on the manuscript. U. Olsson helped with re-drawing the phylogeny. The project was financed by the Max-Planck Institute for Behavioural Physiology, Seewiesen, and by the Konrad Lorenz Institute for Ethology, Vienna. Sabine Tebbich was additionally funded by the European Union (Marie Curie Fellowship).

\section{Appendix}

Appendix 1 Experimental data on explorative behaviour in 13 species of Darwin's finches

\begin{tabular}{lcccc}
\hline Species & Individuals present & Individuals approaching & Sample points & Island \\
\hline Geospiza fuliginosa & 82 & 38 & 42 & St Cruz \\
G. fortis & 40 & 24 & 40 & St Cruz \\
G. magnirostris & 20 & 11 & 20 & St Cruz \\
G. scandens & 13 & 6 & 10 & St Cruz \\
G. conirostris & 23 & 10 & 14 & Genovesa \\
G. difficilis & 22 & 11 & 19 & Genovesa \\
Camarhynchus parvulus & 95 & 50 & 69 & St Cruz \\
C. psittacula & 9 & 2 & 9 & St Cruz \\
C. pauper & 35 & 24 & 25 & Floreana \\
C. pallida & 30 & 9 & 27 & St Cruz \\
Platyspiza crassirostris & 13 & 7 & 13 & St Cruz \\
Certhidae fusca & 28 & 13 & 25 & Genovesa \\
C. olivacea & 106 & 41 & 66 & St Cruz \\
\hline
\end{tabular}

The table shows number of individuals present after attracting them with a bird whistle, number of individuals approaching within three meters or less of the experimental objects (see text), and total number of sample points where the species was recorded 
Appendix 2 Literature data on proportion of foraging time spent on different food items during the wet season in Darwin's finches

\begin{tabular}{|c|c|c|c|c|c|c|c|c|c|}
\hline Species & Island & Reference & Arthropods & FPN & Fruit & Seed & Other & $\begin{array}{l}\text { Plant } \\
\text { fibre }\end{array}$ & $\mathrm{H}$ \\
\hline G. conirostris & Genovesa & $\begin{array}{l}\text { Grant and Grant } \\
\quad(1980)\end{array}$ & 30.1 & 19.7 & 18.6 & 13.9 & & 17.7 & 1.53 \\
\hline G. difficilis & Genovesa & $\begin{array}{l}\text { Grant and Grant } \\
\quad(1980)\end{array}$ & 39.5 & 17.2 & 17.1 & 26 & & 0.2 & 1.32 \\
\hline C. parvulus & St Cruz & $\begin{array}{l}\text { Tebbich et al. } \\
\text { (2004) }\end{array}$ & 45 & 17.38 & 21.1 & 16.6 & 0 & & 1.29 \\
\hline C. psittacula & St Cruz & $\begin{array}{l}\text { Tebbich et al. } \\
\text { (2004) }\end{array}$ & 95.5 & & 4.5 & & & & 0.04 \\
\hline C. pauper & Floreana & $\begin{array}{l}\text { Tebbich } \\
\text { unpublished }\end{array}$ & 38.8 & 10.2 & 34.7 & 12.2 & 0 & 4.1 & 1.36 \\
\hline C. pallida & St Cruz & $\begin{array}{l}\text { Tebbich et al. } \\
\text { (2004) }\end{array}$ & 88.1 & 4.8 & 7.1 & & & & 0.45 \\
\hline P. crassirostris & St Cruz & $\begin{array}{l}\text { Tebbich } \\
\text { unpublished }\end{array}$ & 0 & 20 & 30 & 10 & 0 & 40 & 1.28 \\
\hline C. fusca & Genovesa & $\begin{array}{l}\text { Grant and Grant } \\
\quad(1980)\end{array}$ & 98.5 & 1.5 & & & & & 0.08 \\
\hline C. olivacea & St Cruz & $\begin{array}{l}\text { Tebbich et al. } \\
\text { (2004) }\end{array}$ & 91.5 & 6.4 & 0 & 2.1 & 0 & & 0.34 \\
\hline
\end{tabular}

These data, shown here for different islands, were assumed to reflect diet components and used for calculating the food diversity index (Shannon Diversity Index, H). FPN denotes flowers, pollen and nectar

\section{References}

Bowman RI (1961) Morphological differentiation and adaptation in the Galápagos finches. UC Publ Zool 58:1-302

Bowman RI, Billeb SL (1965) Blood-eating in a Galápagos finch. Living Bird 4:29-44

Bruner PI (1974) Behaviour, ecology and taxonomic status of three south eastern Pacific warblers of the genus Acrocephalus. Unpublished MSc Thesis, Church College, Hawaii

Chance MRA, Meade AP (1955) Competition between feeding and exploration in the rat. Behaviour 8:174-182

Coleman SL, Mellgren RL (1994) Neophobia when feeding alone or in flocks in zebra finches, Taeniopygia guttata. Anim Behav 48:903-907

Curio E, Kramer P (1964) Vom Mangrovenfinken Cactospiza heliobates (Snodgrass und Heller). Z Tierpsychol 21:223-234

Day RL, Coe RL, Kendal JR, Laland KL (2003) Neophilia, innovation and social learning: a study of intergeneric differences in callitrichid monkeys. Anim Behav 65:559-571

Dvorak M, Vargas H, Fessl B, Tebbich S (2004) On the verge of extinction: a survey of the mangrove finch Cactospiza heliobates and its habitat on the Galápagos Islands. Oryx 38:171-179

Ebenman B, Nilsson SG (1982) Components of niche width in a territorial bird species: habitat utilisation in males and females of the chaffinch (Fringilla coelebs) on islands and mainland. Am Nat 119:331-344

Eibl-Eibesfeldt I (1961) Über den Werkzeuggebrauch des Spechtfinken Camarhynchus pallidus (Slater und Slavin). Z Tierpsychol 18:343-346

Ellis JE, Wiens JA, Rodel CF, Anway JC (1976) A conceptual model of diet selection as an ecosystem process. J Theor Biol 60:93-108

Felsenstein J (1985) Phylogenies and the comparative method. Am Nat 125:1-15

Glickman S, Sroges R (1966) Curiosity in zoo animals. Behaviour 26:151-188

Grant PR (1985) Climatic fluctuations on the Galápagos Islands and their influence on Darwin's finches. Ornithol Monogr 36:471-483 
Grant PR (1986) Ecology and evolution of Darwin's finches. Princeton University Press, Princeton

Grant PR, Grant BR (1980) The breeding and feeding characteristics of Darwin's finches on Isla Genovesa, Galápagos. Ecol Monogr 50:381-410

Grant PR, Grant BR (1997) The rarest of the Darwin's finches. Conserv Biol 11:119-126

Greenberg R (1983) The role of neophobia in determining the degree of foraging specialisation in some migrant warblers. Am Nat 122:444-453

Greenberg R (1984) Differences in feeding neophobia in the tropical migrant woodwarblers Dendroica castanea and D. pensylvanica. J Comp Psychol 98:131-136

Greenberg R (1990) Feeding neophobia and ecological plasticity-a test of the hypothesis with captive sparrows. Anim Behav 39:375-379

Greenberg R, Mettke-Hofmann C (2001) Ecological aspects of neophobia and neophilia in birds. In: Nolan V Jr, Thompson CF (eds) Current ornithology, vol 16. Kluwer Academic/Plenum Publishers, New York, pp 119-178

Harvey PH, Pagel MD (1991) The comparative method in evolutionary biology. Oxford University Press, Oxford

Heinrich B (1995) Neophilia and exploration in juvenile common ravens Corvus corax. Anim Behav 50:695-704

Holyoak DT (1973) Notes on the birds of Rangiora, Tuamotu Archipelago and the surrounding ocean. Bull British Ornithologist Club 93:26-32

Hughes RN (1997) Intrinsic exploration in animals: motives and measurements. Behav Process 41:213-226

Jackson MH (1993) Galápagos, a natural history. University of Calgary Press, Alberta

Katzir G (1982) Relationships between social structure and response to novelty in captive jackdaws, Corvus monedula L., I. Response to novel space. Behaviour 81:231-259

Mank JE, Avise JC (2006) Cladogenetic correlates of genomic expansions in the recent evolution of actinopterygiian fishes. Proc Roy Soc Lond B 273:33-38

Mettke C (1995) Exploratory-behaviour in parrots-environmental adaptation. J Ornithol 136:486-471

Mettke-Hofmann C, Winkler H, Leisler B (2002) The significance of ecological factors for exploration and neophobia in parrots. Ethology 108:249-272

Montgomery KC (1955) The relation between fear induced by novel stimulation and exploratory behavior. J Comp Physiol Psychol 48:254-260

Morse DH (1980) Variability in foraging patterns. In: Morse DH (ed) Behavioural mechanisms of ecology. Harvard University Press, Cambridge Mass, pp 4-50

Pellis SM (1981) Exploration and play in the behavioural development of the Australian Magpie Gynmorhina tibican. Bird Behaviour 3:37-49

Petren K, Grant BR, Grant PR (1999) A phylogeny of Darwin's finches based on microsatellite DNA length variation. Proc Roy Soc Lond B 266:321-329

Petren K, Grant PR, Grant BR, Keller LF (2005) Comparative landscape genetics and the adaptive radiation of Darwin's finches: the role of peripheral isolation. Mol Ecol 14:2943-2957

Price T (1997) Correlated evolution and independent contrasts. Phil Trans Roy Soc Lond B 352:519-529

Pulliam R (1986) Niche expansion and contraction in a variable environment. Am Zool 26:71-79

Purvis A, Rambaut A (1995) Comparative analysis by independent contrasts (CAIC): an Apple Macintosh application for analysing comparative data. Comp Appl Biosc 11:247-251

Russel EM, Pearce GA (1971) Exploration of novel objects by marsupials. Behaviour 40:312-322

Sato A, O'hUigin C, Figueroa F, Grant PR, Grant BR, Tichy H, Klein J (1999) Phylogeny of Darwin's finches as revealed by mtDNA sequences. Proc Natl Acad Sci USA 96:5101-5106

Sherry TW (1990) When are birds dietarily specialized? Distinguishing ecological from evolutionary approaches. Stud Avian Biol 13:337-352

Stöwe M, Bugnyar T, Heinrich B, Kotrschal K (2006) Effects of group size on approach to novel objects in ravens (Corvus corax). Ethology 112:1079-1088

Tebbich S, Taborsky M, Fessl B, Dvorak M, Winkler H (2004) Feeding behavior of four arboreal Darwin's finches: adaptations to spatial and seasonal variability. Condor 106:95-105

Thorpe WH (1956) Learning and instinct in animals. Methuen and Co Ltd, London

Tonnis B, Grant PR, Grant BR, Petren K (2005) Habitat selection and ecological speciation in Galápagos warbler finches (Certhidea olivacea and Certhidea fusca). Proc Roy Soc Lond B 272:819-826

Webster SJ, Lefebvre L (2000) Neophobia by the Lesser-Antillean bullfinch, a foraging generalist, and the bananaquit, a nectar specialist. Wilson Bull 112:424-427

Webster SJ, Lefebvre L (2001) Problem solving and neophobia in a columbiform-passeriform assemblage in Barbados. Anim Behav 62:23-32

Winkler H, Leisler B (1999) Exploration and curiosity in birds: functions and mechanisms. In: Proceedings of the 22nd international ornithological congress, Durban, pp 915-932 
Yeaton RI (1974) The ecological analysis of chaparral and pine forest bird communities on Santa Cruz Island and mainland California. Ecology 55:959-937

Yeaton RI, Cody ML (1974) Competitive release in island song sparrow populations. Theor Popul Biol $5: 42-58$

Zink RM (2002) A new perspective on the evolutionary history of Darwin's finches. Auk 119:864-871 